\title{
BMJ Open Health-related quality of life variations by sociodemographic factors and chronic conditions in three metropolitan cities of South Asia: the CARRS study
}

\author{
Kavita Singh, ${ }^{1,2,3,4}$ Dimple Kondal, ${ }^{1,2,3}$ Roopa Shivashankar, ${ }^{1,2,3}$ \\ Mohammed K Ali, ${ }^{1,5,6}$ Rajendra Pradeepa, ${ }^{7}$ Vamadevan S Ajay, ${ }^{1,2,3}$ \\ Viswanathan Mohan, ${ }^{7}$ Muhammad M Kadir, ${ }^{8}$ Mark Daniel Sullivan, ${ }^{9}$ Nikhil Tandon, ${ }^{1,4}$ \\ K M Venkat Narayan, ${ }^{1,5,6}$ Dorairaj Prabhakaran ${ }^{1,2,3,10}$
}

To cite: Singh K, Kondal D, Shivashankar R, et al. Healthrelated quality of life variations by sociodemographic factors and chronic conditions in three metropolitan cities of South Asia: the CARRS study. BMJ Open 2017;7:e018424. doi:10.1136/ bmjopen-2017-018424

- Prepublication history and additional material for this paper are available online. To view please visit the journal (http:// dx.doi.org/10.1136/bmjopen2017-018424).

Received 27 June 2017 Revised 7 September 2017 Accepted 11 September 2017

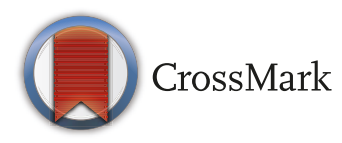

For numbered affiliations see end of article.

Correspondence to Dr Dorairaj Prabhakaran; dprabhakaran@ccdcindia.org

\section{ABSTRACT}

Objectives Health-related quality of life (HRQOL) is a key indicator of health. However, HRQOL data from representative populations in South Asia are lacking. This study aims to describe HRQOL overall, by age, gender and socioeconomic status, and examine the associations between selected chronic conditions and HRQOL in adults from three urban cities in South Asia.

Methods We used data from 16287 adults aged $\geq 20$ years from the baseline survey of the Centre for Cardiometabolic Risk Reduction in South Asia cohort (2010-2011). HRQOL was measured using the European Quality of Life Five Dimension-Visual Analogue Scale (EQ5D-VAS), which measures health status on a scale of 0 (worst health status) to 100 (best possible health status). Results 16284 participants completed the EQ5D-VAS. Mean age was $42.4( \pm 13.3)$ years and $52.4 \%$ were women. $14 \%$ of the respondents reported problems in mobility and pain/discomfort domains. Mean VAS score was 74 (95\% Cl 73.7 to 74.2$)$. Significantly lower health status was found in elderly (64.1), women (71.6), unemployed (68.4), less educated (71.2) and low-income group (73.4). Individuals with chronic conditions reported worse health status than those without (67.4 vs 76.2 ): prevalence ratio, $1.8(95 \% \mathrm{Cl} 1.61$ to 2.04$)$.

Conclusions Our data demonstrate significantly lower HRQOL in key demographic groups and those with chronic conditions, which is consistent with previous studies. These data provide insights on inequalities in population health status, and potentially reveal unmet needs in the community to guide health policies.

\section{INTRODUCTION}

Health-related quality of life (HRQOL) is a multidimensional concept that provides a broader perspective of health through conveying an individual's ability to function in physical, mental and social domains of life. ${ }^{1}$ HRQOL is thus an essential patient-centred outcome measure that is useful to guide health policies. ${ }^{23}$ HRQOL is preferred over other health indicators (life expectancy,

\section{Strengths and limitations of this study}

- This is the first population-level health-related quality of life (HRQOL) data from South Asia using the European Quality of Life Five Dimension-Visual Analogue Scale including three large metropolitan cities in India and Pakistan with a large sample size (16284 adults aged $\geq 20$ years).

- Our data provide the first baseline values to be used for monitoring population health status and analysed the relationships between selected chronic conditions and HRQOL.

- HRQOL data presented in this article could be used to complement national health targets by providing a measure of chronic disease burden based on perceived health status rather than solely on mortality and disease prevalence.

- Due to the cross-sectional nature of the data, the causal relationship between socioeconomic parameters or chronic conditions and HRQOL cannot be determined.

- Many chronic conditions (respiratory, locomotor, cancer and others) were not included in the survey. Therefore, the ranking of most severe health conditions and associated HRQOL is not complete.

mortality, morbidity) for measuring chronic disease burden as it incorporates both length and quality of life. ${ }^{4}$ In South Asia, chronic conditions (diabetes, hypertension and heart diseases) occur at an early age, ${ }^{5}$ with detrimental effects on length and quality of life. ${ }^{6}$ In addition, episodes and fear of hypoglycaemia, recurrent heart attacks, stroke and other long-term complications (kidney diseases, diabetic retinopathy) are not always measured as such, although they have a substantial adverse impact on an individual's overall health status. ${ }^{8}$ Therefore, it is important to quantify the effect of chronic conditions on individuals' HRQOL. 
There are several disease-specific (Chronic Respiratory Distress Questionnaire, Arthritis Impact Measurement Scale) and generic instruments (Short Form 36, WHO-Quality of Life Questionnaire and the European Quality of Life Five Dimension-Visual Analogue Scale (EQ5D-VAS)) available to measure population HRQOL. ${ }^{4-18}$ However, the EQ5D-VAS is favoured because it is generic, not specific to a particular disease, and it includes multidimensional measures of health profile in five dimensions (mobility, self-care, usual activities, pain/discomfort and anxiety/depression) and the single-dimensional measure VAS to summarise overall health status. ${ }^{1}$ Also, EQ5D-VAS has been applied and validated for its use in many population surveys across the world; therefore, it makes the comparison of health status across populations easier.

Data on population HRQOL across socioeconomic status (SES) from South Asia are scarce, and little is known about the relative associations between different chronic conditions and individual HRQOL. The Centre for Cardiometabolic Risk Reduction in South Asia (CARRS) study ${ }^{19}$ had collected data on both EQ5D-VAS and selected chronic conditions from a large representative population of adults in urban South Asia. We used this opportunity to examine population HRQOL in this region. In this paper, we describe the variations in HRQOL by age, gender and SES, and explore the relationships between selected chronic conditions and HRQOL in a representative sample of adults aged $\geq 20$ years from three metropolitan cities in India and Pakistan. We also analysed the relationship between multidimensional EQ5D measures and single-dimensional VAS across major subgroups.

\section{METHODS}

\section{Study design and setting}

We obtained data from the baseline cross-sectional survey of the CARRS cohort (2010-2011), which recruited a representative sample of non-pregnant adults aged $\geq 20$ years from three urban cities: Chennai, Delhi and Karachi. These metropolitan cities with large and heterogeneous populations in terms of demographic profile and economic transitions offer unique opportunities to assess variations in health status across different socioeconomic groups. The detailed CARRS study design has been published elsewhere. ${ }^{19}$ Briefly, a multistage cluster random sampling strategy was used with wards (in Delhi and Chennai) or clusters (in Karachi) as the primary sampling units. Using the WHO STEPS (STEPwise approach to surveillance) survey 'Kish method', two participants, one male and one female, aged $\geq 20$ years (non-pregnant) and meeting the study eligibility criteria, were selected from each randomly selected household. ${ }^{19}$

\section{Study measures}

Comprehensive and uniform data collection instruments were used to capture measurements in all three sites. A summary of all surveillance measures, methods and instruments used in the study has been published in detail. ${ }^{19}$ Briefly, a questionnaire was administered to collect information regarding demographic, socioeconomic, behavioural, and past and present health status of the participant.

Trained study staff measured anthropometric parameters (height, weight) using standardised techniques and blood pressure (BP) twice at each participant's home or at a medical camp organised in the community, after $5 \mathrm{~min}$ in a seated position using an electronic BP measuring device (Omron Dalian, Liaoning Sheng, China). If the difference between the first two systolic or diastolic BP readings was more than $10 \mathrm{~mm} \mathrm{Hg}$ or $5 \mathrm{~mm} \mathrm{Hg}$, respectively, a third reading was taken. Average BP readings of the two/three readings were recorded in the study database. Additionally, fasting blood glucose (FBG) and glycated haemoglobin (HbAlc) were measured. The overall response rates were $94.7 \%$ for questionnaire completion and $84.3 \%$ for blood tests.

Population health status was measured using the EQ5D-VAS questionnaire, which consisted of two components: health state description and self-rated health status on VAS. Health state description (profile) includes five dimensions (5D): mobility (walking ability), self-care (ability to wash or dress by oneself), usual activities (ability to work, study, housework), pain/discomfort and anxiety/depression. The respondents self-rate their level of severity for each dimension using three levels (EQ5D3L): having no problems, having some or moderate problems, or being unable to do/having extreme problems. The respondents were asked to choose one of the statements that best described their health status on the surveyed day. For example, three levels of 'mobility' dimension were phrased as 'I have no problems in walking', 'I have some problems in walking' and 'I am confined to bed'. Given the possible permutations of different domains and response types, there are potentially $243\left(=3^{5}\right)$ different health profiles.

For overall health status, the respondents evaluated their health status using the VAS. The VAS asks respondents to mark health status on the day of the interview on a scale of 0 (worst health status) to 100 (best imaginable health status).

\section{Covariates}

Self-reported age at baseline in completed years was used and categorised into 20-24, 25-34, 35-44, 45-54, 55-64, $65-74$ and $\geq 75$. Based on participant responses, we categorised employment status into employed, student, housewife, retired and unemployed. Income class was grouped into three categories based on household monthly income: low-income, less than 10000 Indian rupees (equivalent to US\$200); middle-income, 10000-20 000 Indian rupees (US\$200-400); and high-income strata, greater than 20000 Indian rupees (US\$400). We categorised highest education level attained into three categories: up to primary, secondary schooling and graduates. The marital status was classified as single, married, widowed and divorced. Body 
mass index $\left(\mathrm{kg} / \mathrm{m}^{2}\right)$ international classification of $\leq 17.9$ was used to define underweight, 18.0-24.9=normalweight, 25.0-29.9=overweightand $\geq 30.0=$ obese. Lifestyle habits like tobacco use were classified based on self-reports as never, former and current user. Data on chronic conditions consisted of self-reported hypertension, diabetes, heart disease, stroke and kidney disease. In addition, diabetes was categorised into self-reported, newly diagnosed (defined by no self-reported diabetes and FBG of $\geq 126 \mathrm{mg} / \mathrm{dL}$ or HbA1c $\geq 6.5 \%$ ), pre-diabetes (no self-reported diabetes and FBG $\geq 100-125 \mathrm{mg} / \mathrm{dL}$ or HbAlc $\geq 5.7 \%-6.4 \%)$ and normoglycaemia (no self-reported diabetes and FBG $<100 \mathrm{mg} / \mathrm{dL}$ and HbAlc <5.7\%). Similarly, we classified hypertension as self-reported, newly diagnosed (no self-reported hypertension and $\mathrm{BP} \geq 140 / 90 \mathrm{~mm} \mathrm{Hg}$ ), prehypertension (no self-reported hypertension and BP 120-139/80-89 mm Hg) and normotensive (no history of hypertension and $\mathrm{BP}<120 / 80 \mathrm{~mm} \mathrm{Hg}$ ).

\section{Ethical considerations}

Study participants provided written informed consent before participation in the study.

\section{Analysis}

We used Stata V.14.0 for data analysis. We used the 'svy' command for all analysis to account for the complex survey design. ${ }^{20}$ Before any of the survey estimation commands were used, the svyset command was used to specify the variables that described the stratification, sampling weight and primary sampling unit variables. This analysis included data obtained from 16284 study participants. All the responses coded as refused, unknown or missing were treated as missing data. The frequency (percentages) and mean were reported to display the level of population health status and the sample characteristics. Percentages of those reporting any problems in EQ5D domains and mean VAS were stratified by respondents' demographic characteristics-age, gender, marital status and SES-education, income and employment status; and health-related indicators-presence of chronic conditions-were reported. Additionally, prevalence ratios of moderate or severe health problems in people with and without chronic conditions were estimated using log binomial regression. Where the model did not reach convergence, Poisson regression model was used. The model was adjusted for sociodemographic covariates (age, gender, marital status, education level and household income) and city. Linear regression analysis was performed to explore the relationship between the VAS and the EQ5D measures across major subgroups. In the regression model, VAS was used as a dependent variable, and EQ5D measures were treated as independent variables.

\section{STUDY RESULTS}

\section{Characteristics of the study population}

A total of 17274 individuals in 10002 households were approached in the three study sites (7596 participants in Chennai, 5420 in Delhi, 4258 in Karachi). From these, a total of 16287 participants were recruited (the overall response rate was $94.3 \%$ at the participant level: 6906 Chennai (90.9\%), 5364 Delhi (98.9\%) and 4017 Karachi $(94.3 \%))$. Detailed baseline characteristics of the CARRS cohort are published elsewhere.$^{21-24}$ Briefly, the mean age was $42.4( \pm 13.3), 52.4 \%$ were female, $61 \%$ completed secondary schooling and the majority of respondents $(72.5 \%)$ reported household income level $<10000$ Indian rupees (US\$200). Two-thirds (66\%) of the study population had BMI $\geq 25$, one-fifth $(20 \%)$ of the respondents reported current tobacco use, and $37.5 \%$ had self-reported chronic conditions (hypertension, diabetes, heart disease, stroke or chronic kidney disease).

\section{Overall HRQOL by age and gender}

A total of 16284 study participants completed the EQ5D-VAS (99.9\%). Overall, the percentage of respondents reporting any problems in mobility and pain/ discomfort ( $14 \%$ each) was higher than for other domains. Greater health problems were observed with higher age for both men and women $(\mathrm{p}<0.001)$ (table 1$)$. Problems with mobility were higher with advancing age. However, problems with anxiety/depression did not show such trend. Average health status (VAS) reported by the CARRS cohort was 74.5 (95\% CI 73.7 to 74.2 ) (figure 1). Women reported lower health status than men (71.6 vs $79.0 ; \mathrm{p}<0.001)$.

Of the respondents $74 \%$ rated a perfect health profile with no difficulties in any EQ-5D domain, and $0.06 \%$ rated the worst health profile whereby they had difficulties with every EQ-5D domain. The distribution of the VAS scores was skewed in the direction of best-imagined health state. Only $0.5 \%$ respondents rated their health status on VAS under 10 , and $10 \%$ rated it under 50 (online supplementary appendix 1).

\section{HRQOL and SES}

Table 2 and Figure 2 depict the mean VAS, percentage and prevalence ratios of respondents reporting moderate or severe problems in the five dimensions, across various subgroups, respectively. Employed adults and students reported better health status than home makers, retired or unemployed participants. We observed almost equal health status in home makers and retired people. Health status was also similar in the middle-income and high-income groups, while it was significantly lower in the low-income group. Individuals with higher education (graduate and above) and high income had higher HRQOL than those with secondary or primary schooling and low-income class. Also, individuals with BMI $\geq 18-24 \mathrm{~kg} / \mathrm{m}^{2}$ reported better health status than those with BMI $\geq 25 \mathrm{~kg} /$ $\mathrm{m}^{2}$. Current tobacco users reported better health status than former tobacco users or non-users. However, in a stratified analysis of HRQOL in tobacco users by presence or absence of chronic conditions, tobacco users with chronic conditions reported worse health status than non-users. 
I) W

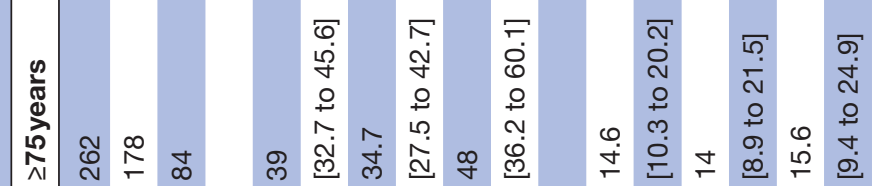

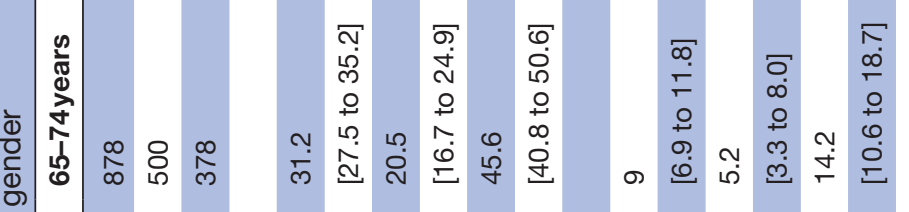

के

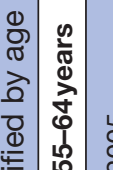

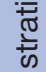

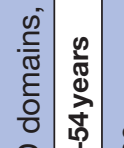

茴

용

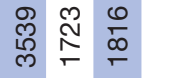

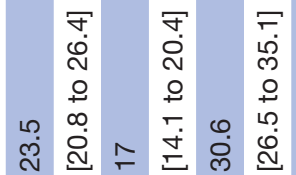

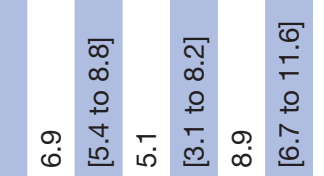

ए न बए

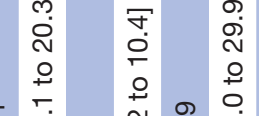

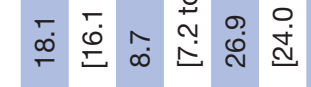

ㄷ क क

$\wedge \stackrel{+}{\infty} \wedge \stackrel{+}{\infty}$ L

$\frac{\frac{\varepsilon}{0}}{\frac{0}{0}}$

$\frac{0}{\frac{m}{w}}$

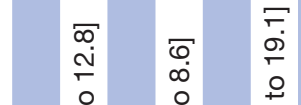

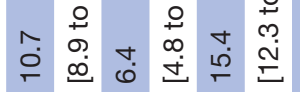

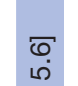

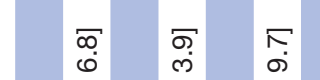

เุ

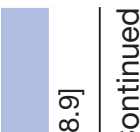

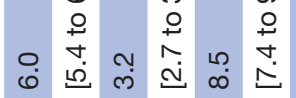

m.

禹芒

F

T.

ז.

우용 웅

Nid

m

政

m

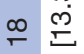

m户 d

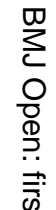

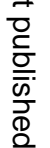

\%

$\vec{\circ}$

$\overrightarrow{\vec{\omega}}$

음.

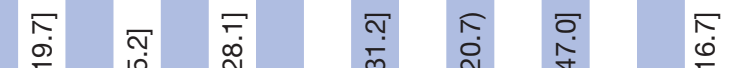

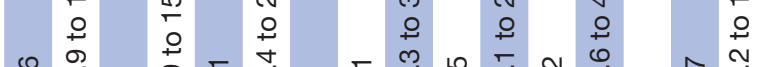

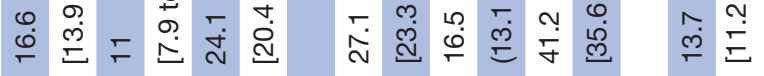

N

$\stackrel{\substack{\dot{0} \\ \infty}}{+\infty}$

$\stackrel{+}{9}$

$\vec{ज}$

웅

F ल के

다

$\stackrel{n}{\mathcal{O}}$

竞

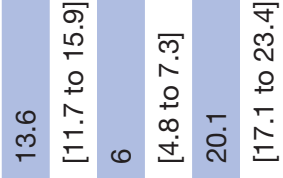

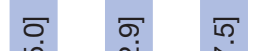

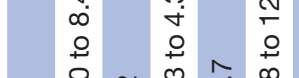

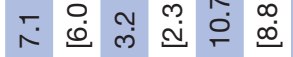

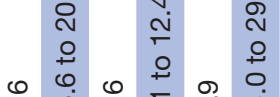

ஸ

官

ब

$\infty$

के

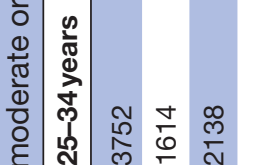

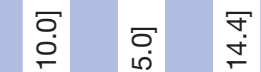

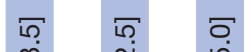

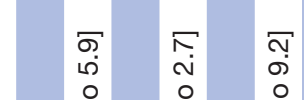

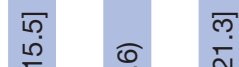

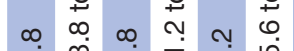

잉

๑

웅ㅇำ

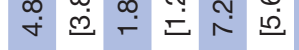

$\stackrel{m}{-} \stackrel{0}{\sim} \stackrel{0}{\varphi} \stackrel{\infty}{\circ}$

๑

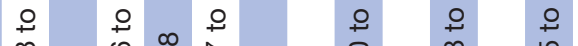

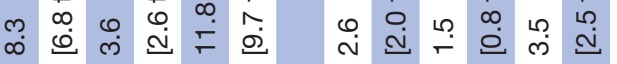

守

бோ ஸุ

$\begin{array}{lll}2 & 0 \\ 0 & 0 & 0 \\ 0 & 0\end{array}$

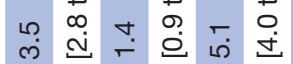

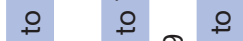

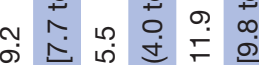

产

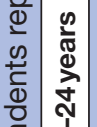

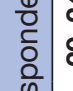

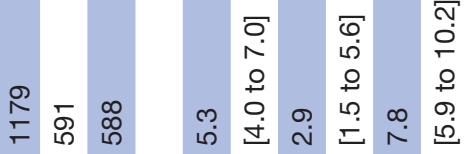

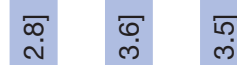

ç

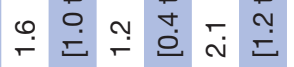

तָ ก ल

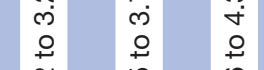

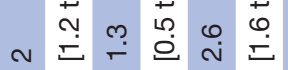

₹

무

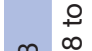

ம்

$\frac{2}{0}$

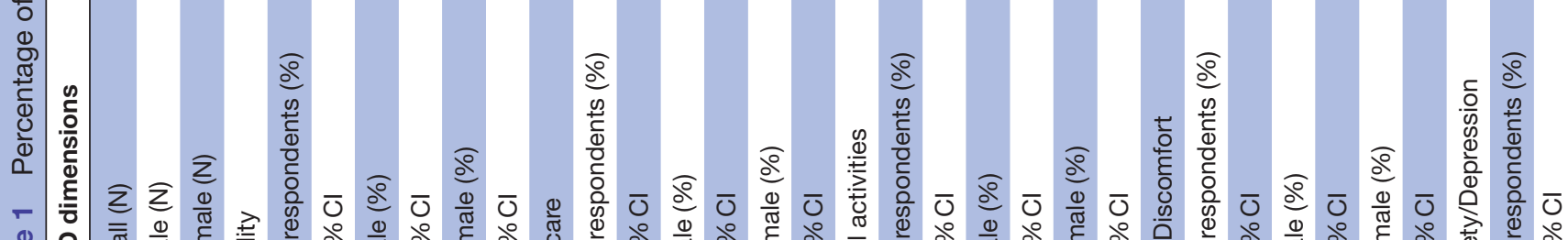

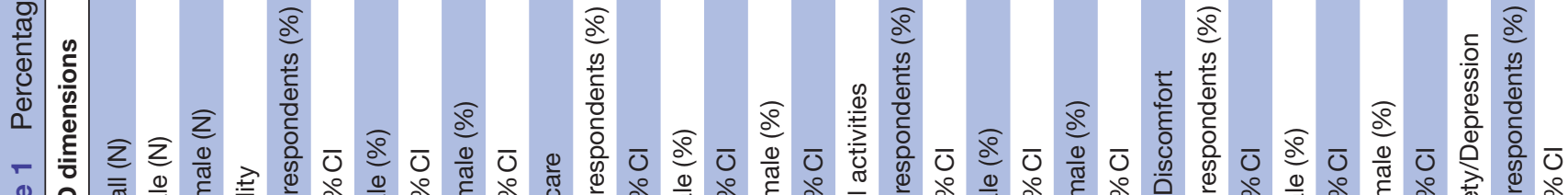

ฮ

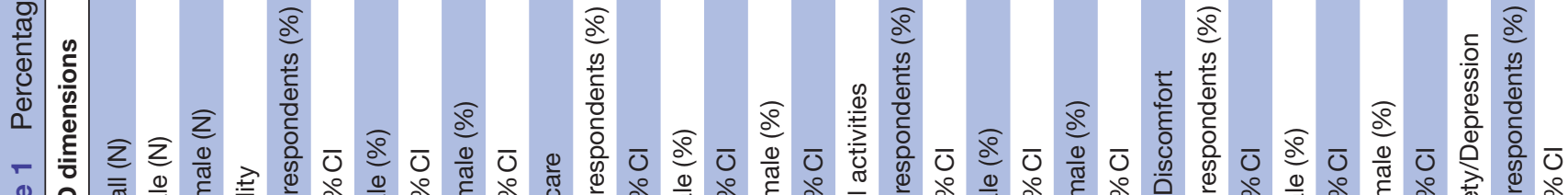

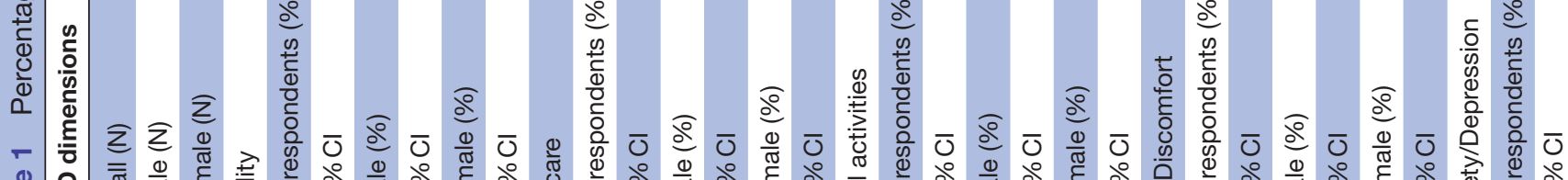

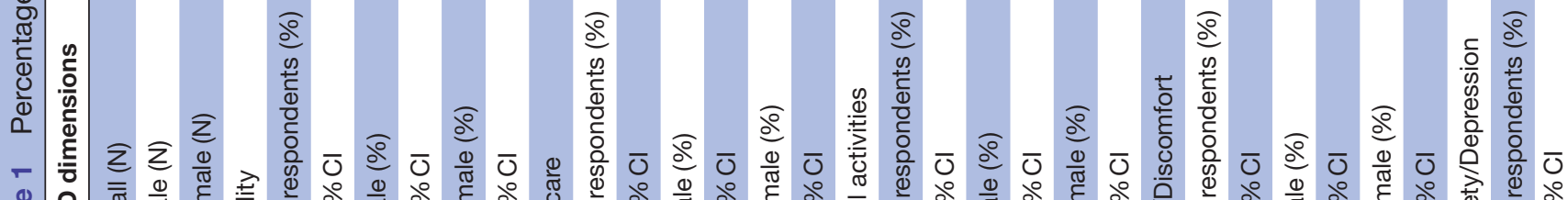

+ 웅

व 0 m N

ஜ

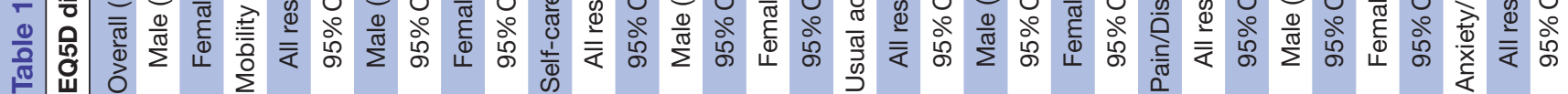




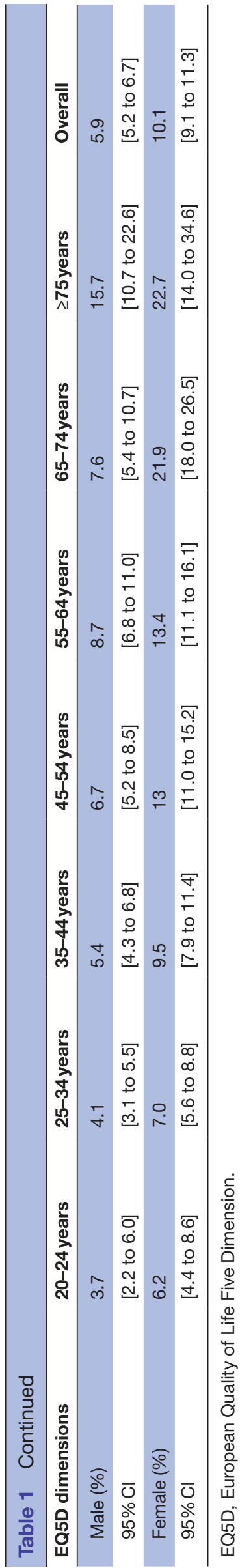

HRQOL and chronic conditions

Overall, individuals with chronic conditions reported lower health status than those without chronic conditions. About half of the respondents with self-reported diabetes, hypertension, stroke, heart disease or chronic kidney disease reported moderate or severe problems in all five domains (table 2).

Table 3 presents the adjusted prevalence ratio of moderate or severe problems among people with versus without chronic conditions, stratified by sex and cities. Individuals with chronic conditions reported two times greater problems in mobility, usual activities domains, pain/discomfort and anxiety/depression, than in individuals without chronic conditions.

Further, a small proportion of individuals with chronic conditions, mostly those with hypertension $(10.5 \%)$ or diabetes $(8.3 \%)$, reported having a perfect health state.

\section{Relationship between VAS and EQ5D measures across major subgroups}

We expected that each EQ5D dimension would have an independent relationship with VAS since each of them represents a different aspect of HRQOL. Online supplementary appendix 2 provides the beta coefficients of the weighted regression models (ie, with the application of the population sampling weights). In the overall population, having any problems in mobility, self-care, pain/ discomfort and anxiety/depression were associated with VAS scores that were 10-12 points lower. This inverse relationship of lower VAS with higher domain difficulties was larger in men, elderly ( $>60$ years), low-income, less educated, divorced and high BMI individuals, compared with their respective counterparts. Tobacco users who reported difficulties in all domains of EQ5D had lower VAS scores (indicating lower quality of life). Kidney disease and stroke were the most disabling conditions on all measures.

\section{DISCUSSION}

Comparative assessments of HRQOL variations by sociodemographic factors and chronic conditions aid in prioritising public health targets for intervention. Results from this study indicate that less than $10 \%$ of the respondents rated their health status as 100 (ie, best-imagined health state) on VAS. Mobility, pain/discomfort and anxiety/ depression were the most commonly reported problems, with the extent of these problems differing across population subgroup. Elderly ( $>60$ years) and women reported significantly greater problems in the mobility, pain/ discomfort and anxiety/depression domains.

The mean VAS in our study was 74.5, which is lower than reported by most Western countries (82.5), but comparable to the results from other low-income and middle-income countries (LMIC) (71.1-77.8) (online supplementary appendix 3). ${ }^{25-28}$ Lower health status reported by urban South Asians can be interpreted in a number of ways. The lower scores may be related 


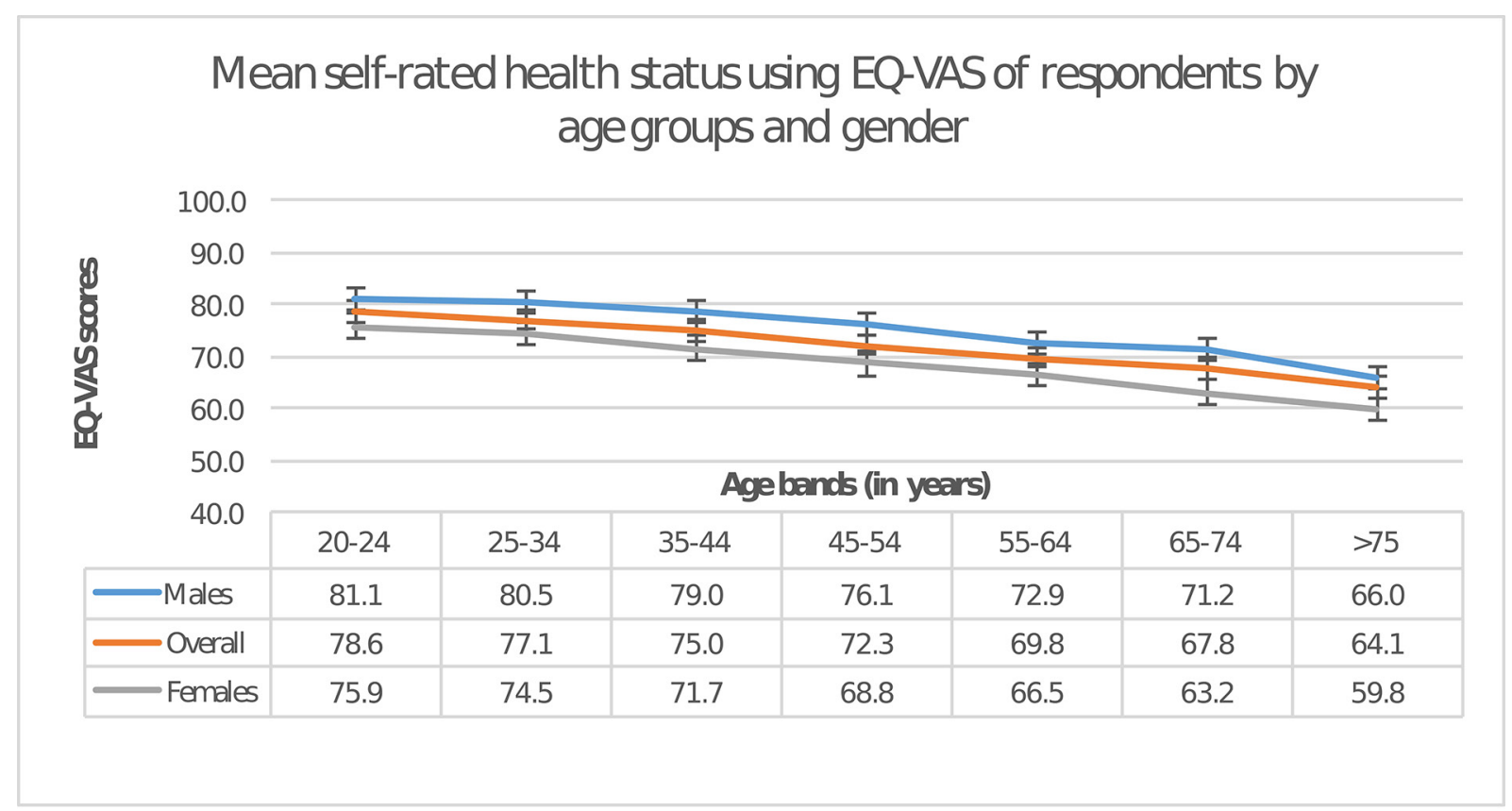

Figure 1 Mean self-rated health status using the European Quality of Life Five Dimension-Visual Analogue Scale (EQ5D-VAS) of respondents by age groups and gender. This figure presents the mean self-rated health status for overall study population by age groups and gender. The EQ5D-VAS measures health status on a scale of 0 (worst health status) to 100 (best imaginable health status). ${ }^{*} p$ Value for difference between mean EQ5D-VAS between men and women at each age group is statistically significant, $p<0.01$.

to generally lower reporting of HRQOL among this group. Alternatively, these scores may reflect morbidity and suboptimal access to healthcare facilities to address health concerns. South Asians experience chronic conditions at relatively younger ages than other race/ethnic groups, and the associated reductions in productivity and income levels may be manifested in these self-reported EQ5D-VAS scores.

A higher percentage of individuals reported problems in mobility dimension $(14 \%-17 \%)$ in South Asia, which is comparable to results from other LMICs. ${ }^{29}$ However, problems in anxiety/depression are pretty low in South Asia when compared with the rest of the world; this could be due to underdiagnoses of depression-related problems or stigma attached to these health conditions. These patterns could also reflect differences in how adults in different parts of the world self-rate their health.

Worse health status in retired or home makers, compared with employed persons, may be related to being homebound or reflect underlying illnesses that may be the factor driving these participants to be homebound and not employed.

In terms of modifiable risk factors, maintaining a healthy BMI cut-off $\left(18-25 \mathrm{~kg} / \mathrm{m}^{2}\right)$ is favoured because individuals with BMI $<18 \mathrm{~kg} / \mathrm{m}^{2}$ and $\geq 25 \mathrm{~kg} / \mathrm{m}^{2}$ reported greater problems in all five domains. Although previous studies have shown that lower levels (intensity) of tobacco use are linked with higher HRQOL and regular tobacco users with worse health status, ${ }^{30} 31$ in our study, former tobacco users reported lower HRQOL than current users. This finding may indicate reverse causality, that is, former tobacco users after experiencing an illness would have quit smoking/tobacco. Further, supported by the fact that tobacco users with chronic conditions or greater difficulties in EQ5D domains had lower VAS scores is suggestive that morbidity and not the habit of tobacco use per se is more closely related to participants' perception of health. However, a causal link between tobacco use and HRQOL cannot be confirmed in this cross-sectional study. Longitudinal analyses of the independent associations between the smoking/tobacco with HRQOL may provide a better understanding of this relationship.

Notably, one in five individuals living with known hypertension or diabetes (average disease duration 4years) still reported a perfect health state, indicating that these individuals may feel asymptomatic until they experience a clinical event. Also, very small proportions of patients with heart disease and stroke (with longer duration of illness; average 9years) reported perfect health states, suggesting that these individuals may have adapted to their conditions over time and may be benefiting from treatment and self-care that improve their self-rated quality of life. However, we did not investigate whether these other factors like adherence influence quality of life in those living with chronic conditions.

Due to the differences in statistical analyses, HRQOL measures, sociodemographic characteristics of the sample and medical conditions selected, the results of this study may not be directly comparable to reports from other countries. ${ }^{32}$ Nevertheless, a few differences and common findings are noteworthy. Individuals with stroke or chronic kidney disease rated the lowest health status, 


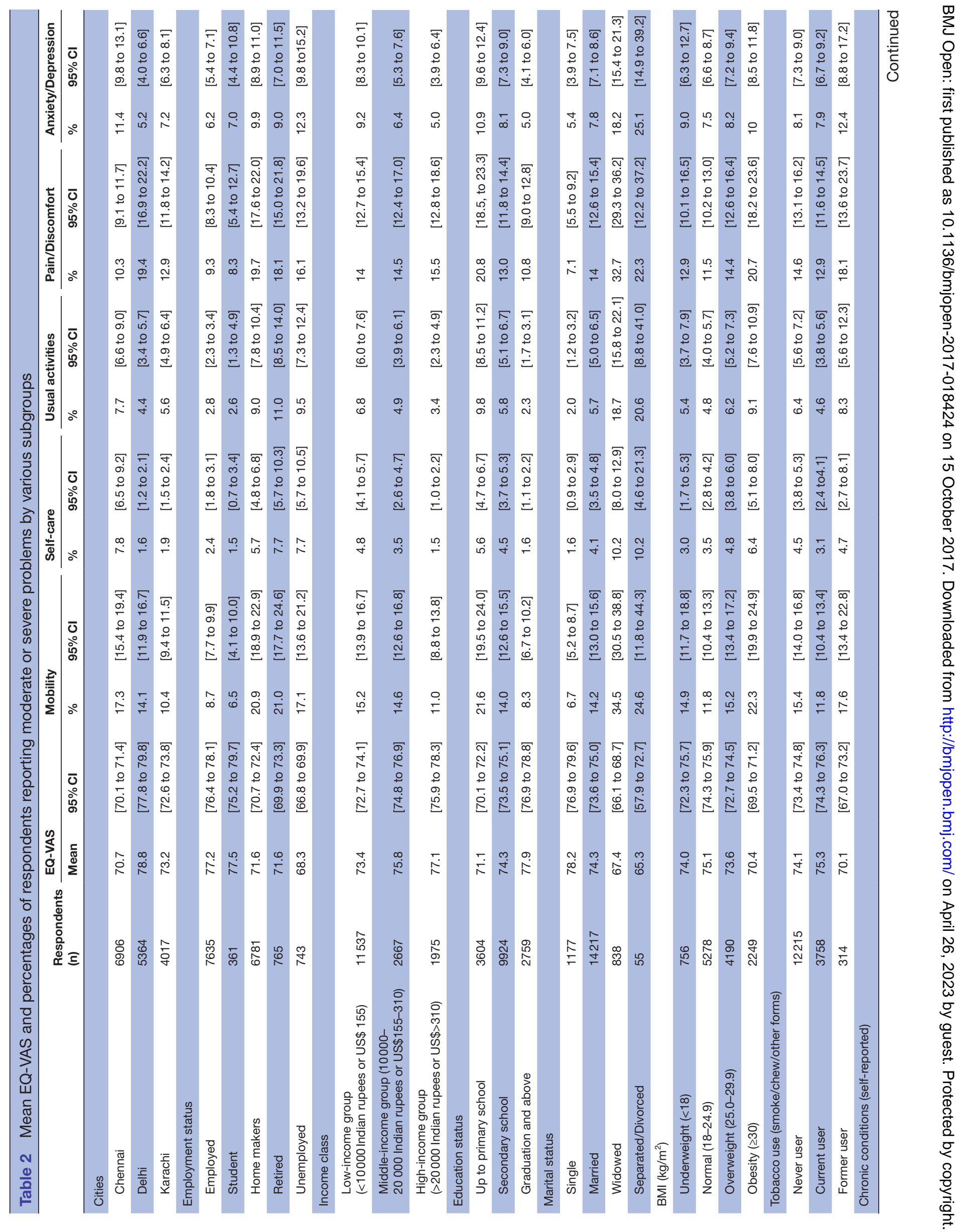




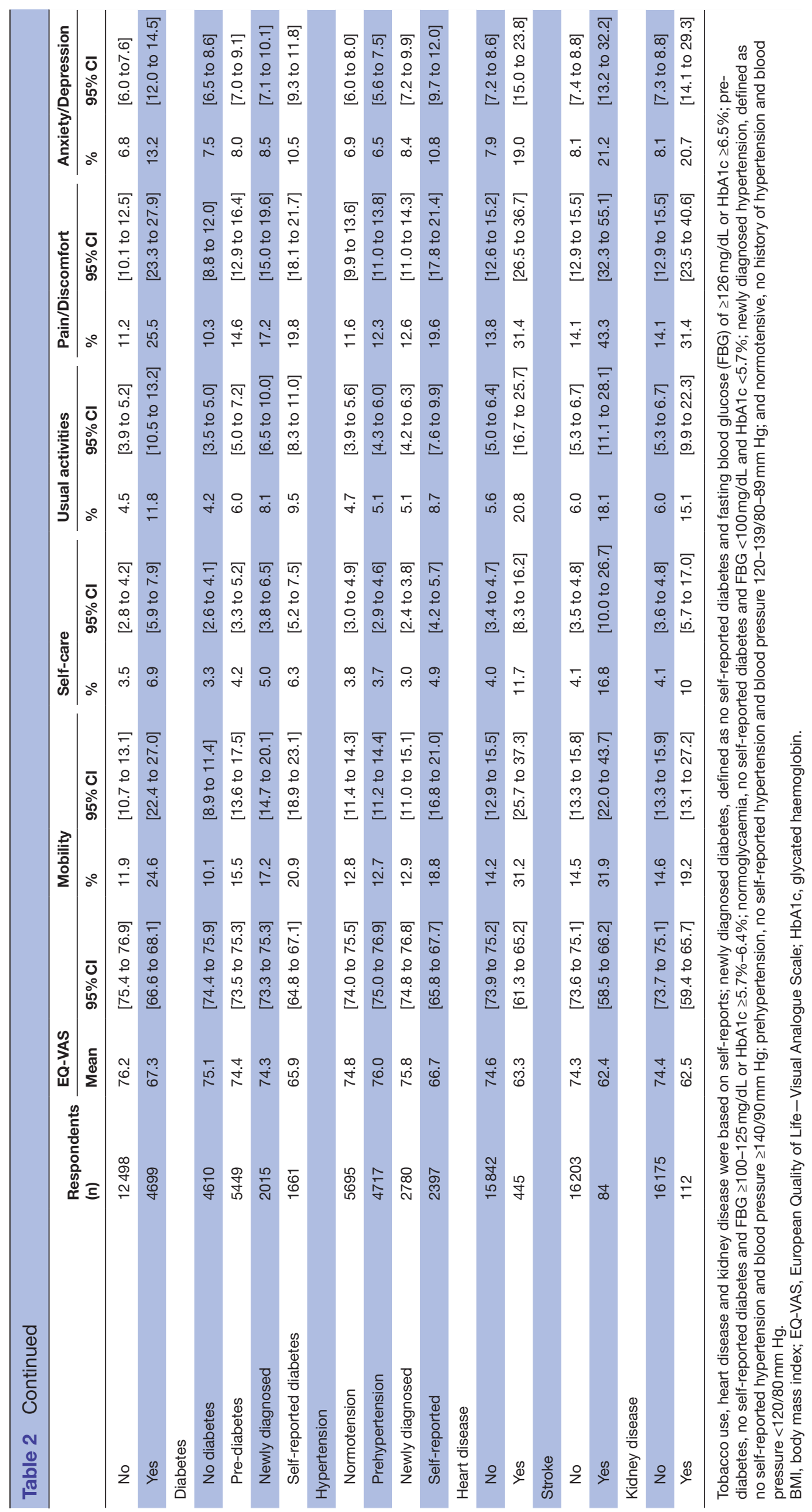




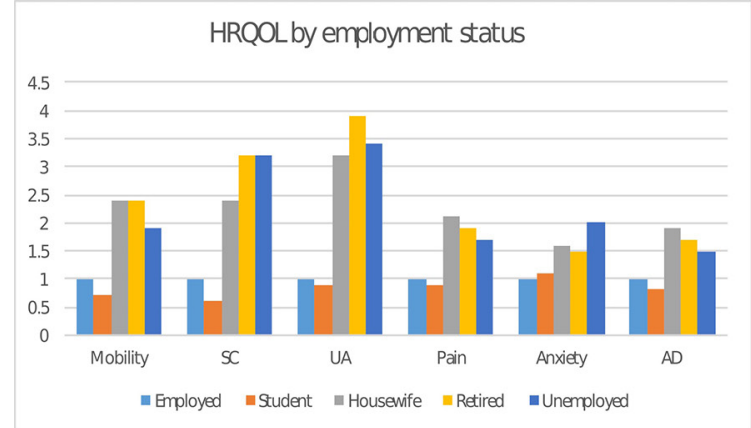

A

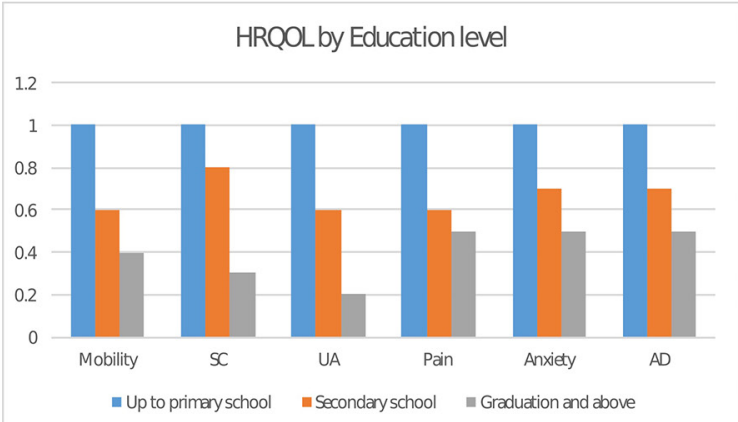

C

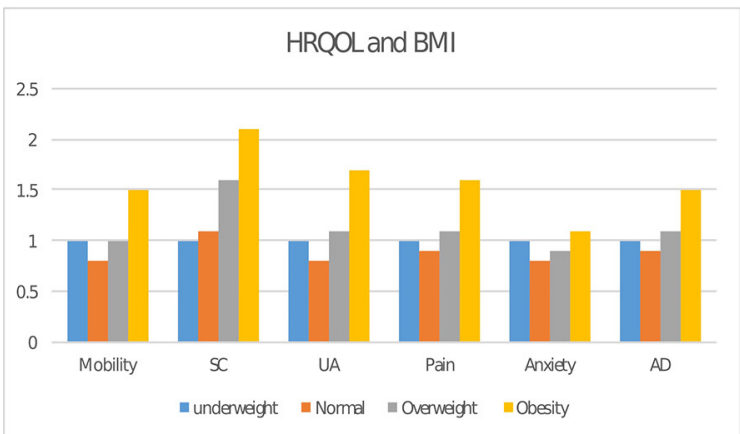

E

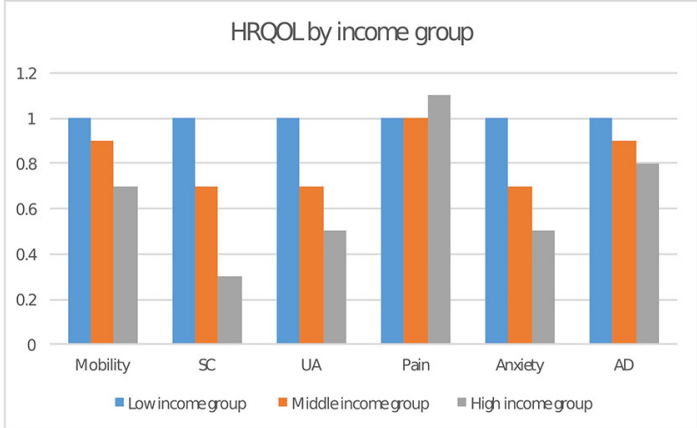

B

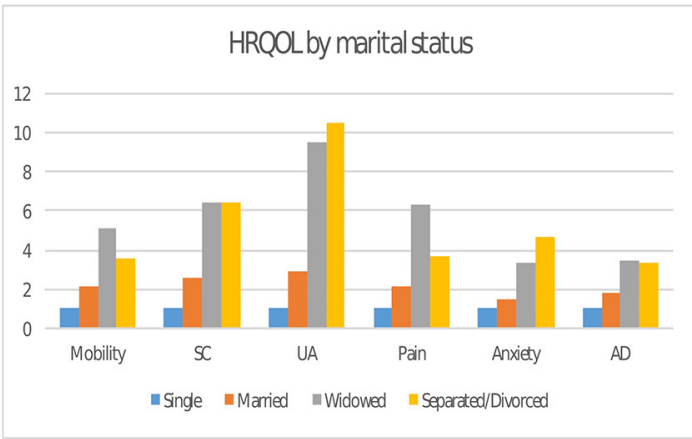

D

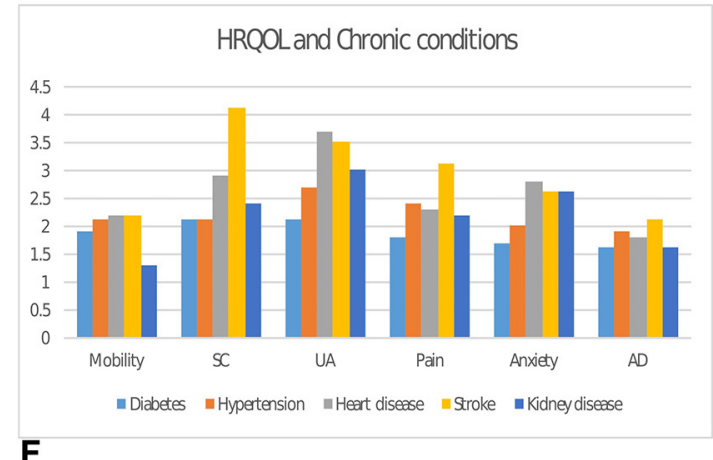

Figure 2 PR of moderate or severe health problems by sociodemographic factors and chronic conditions. (A) Shows the PR of moderate or severe difficulties in EQ5D domains (mobility, self-care, usual activities, pain/discomfort, anxiety/ depression and any of the five dimensions) by employment status. With reference to those who were employed (PR=1), housewife, retired and the unemployed reported greater problems in all five domains, whereas students only reported higher anxiety problems compared with employed. (B) Shows the PR of moderate or severe difficulties in EQ5D domains by income group. With reference to low-income group $(\mathrm{PR}=1)$, those in middle-income or high-income groups had less problems in all five domains. (C) Shows the PR of moderate or severe difficulties in EQ5D domains (mobility, self-care, usual activities, pain/discomfort, anxiety/depression and any of the five dimensions) by education level. With reference to those primary school education $(\mathrm{PR}=1)$, individuals with secondary school or graduates reported significantly lower problems in all five domains. (D) Shows the PR of moderate or severe difficulties in EQ5D domains by marital status. With reference to single $(P R=1)$, those who were married, widower or divorcee had greater problems in all five domains. (E) Shows the PR of moderate or severe difficulties in EQ5D domains (mobility, self-care, usual activities, pain/discomfort, anxiety/depression and any of the five dimensions) by BMI. With reference to underweight, that is, $\mathrm{BMI}<18 \mathrm{~kg} / \mathrm{m}^{2}(\mathrm{PR}=1)$, individuals who are overweight (BMI $25-$ $29.9 \mathrm{~kg} / \mathrm{m}^{2}$ ) or obese $\left(\mathrm{BMI} \geq 30 \mathrm{~kg} / \mathrm{m}^{2}\right.$ ) reported significantly greater problems in all five domains. (F) Shows the PR of moderate or severe difficulties in EQ5D domains by chronic conditions. Compared with those without chronic conditions, individuals with self-reported diabetes, hypertension, heart disease, stroke and kidney disease had twice greater problems in all five domains. AD, any dimension; BMI, body mass index; EQ5D, European Quality of Life Five Dimension; HRQOL, health-related quality of life; PR, prevalence ratio; SC, self-care; UA, usual activities.

which is consistent with results reported from other studies done in China, Thailand and Western populations. ${ }^{2833-36}$ Since the respondent's health status could be affected by how well the condition was managed, caution is needed in interpreting study results regarding the relative effect of chronic conditions on HRQOL. ${ }^{37-41}$ A more 


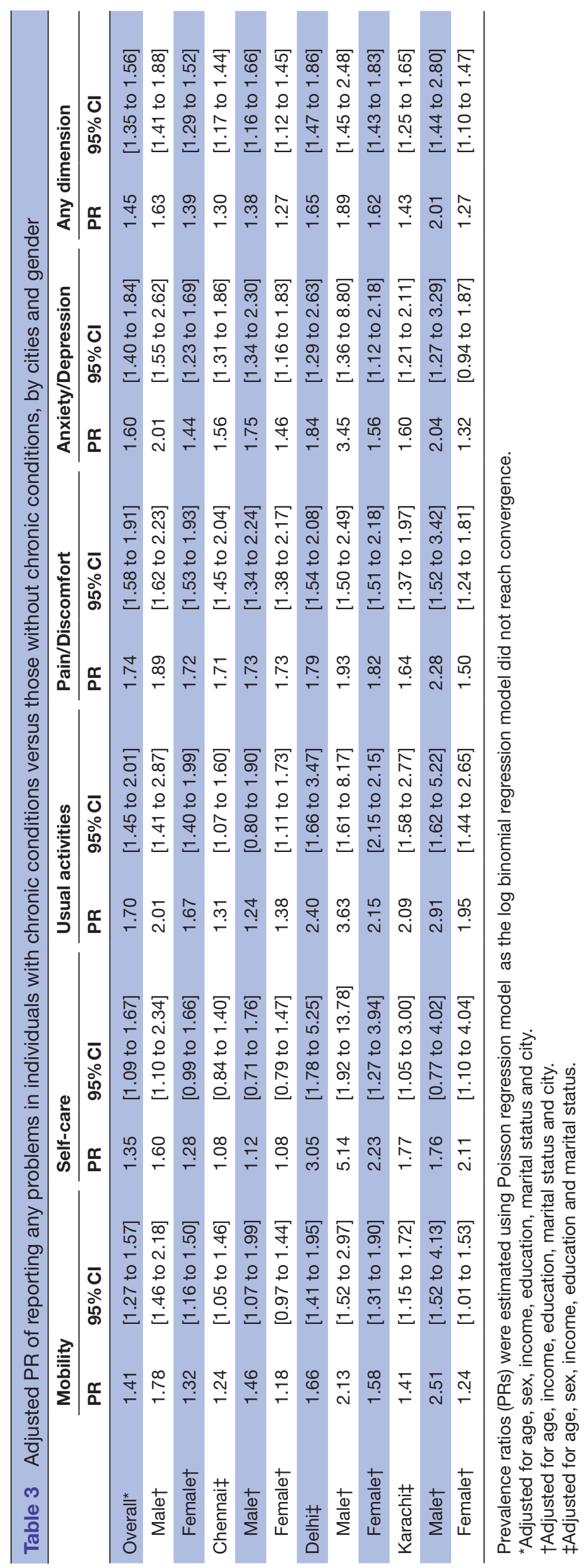


recent Canadian study conducted by Mo $e t a t^{42}$ indicated a strong relationship between low Health Utility Index scores and certain chronic conditions. The authors found that arthritis/rheumatism, heart disease, hypertension, cataracts and diabetes had a negative impact on HRQOL. In the USA, Medical Expenditure Panel Survey data-based study reported that, after adjusting for sociodemographic variables, all of the selected chronic conditions were associated with lower EQ5D scores, with effects greatest for emphysema, followed by heart disease, stroke, high BP, diabetes and asthma. ${ }^{434}$

\section{Strengths and limitations of this study}

To our knowledge, this is the first population-level HRQOL data from South Asia using EQ5D-VAS including three large metropolitan cities in India and Pakistan with a large sample size that has used multistage cluster random sampling strategy and standardised protocols and measurement tools across sites. Our data provide the first baseline values to be used for monitoring population health status and analysed the relationships between selected chronic conditions and HRQOL. This information could be used to complement national targets by providing a measure of chronic disease burden based on perceived health status rather than solely on mortality and disease prevalence. In our secondary data analysis, EQ5D and VAS measures correlated well, which confirms the convergent and discriminate validity of the EQ5D instrument.

There are several limitations to this study. First, due to the cross-sectional nature of the data, the causal relationship between socioeconomic parameters/chronic conditions and HRQOL cannot be determined and is not implied. Second, many chronic conditions (respiratory, locomotor, cancer and others) were not included in the survey. Therefore, the ranking of most severe health conditions and associated HRQOL is not complete. Third, the selected chronic conditions were self-reported, and the study investigators did not examine the accuracy of information. However, this poses less of a threat to validity because self-reporting of heart diseases, stroke and kidney diseases is pretty accurate in community surveys. ${ }^{45-48}$ Further, hypertension and diabetes were measured in this study using standardised methods. Lastly, EQ5D data were self-reported and the variation in how individuals perceive disability varies widely. However, this should be less of a problem given the large sample size in this study. Fourth, the findings of this study may not be replicable if researchers use a different HRQOL instrument, ${ }^{49-54}$ which can be tested in a future study.

\section{Public health relevance and policy implications}

HRQOL data from this study provide baseline values for monitoring variations in health for specific population groups on the basis of gender, education, employment, income, presence of chronic conditions and place of residence. These data are also relevant to assess the overall burden of physical and mental health problems that are not disease-specific. In aggregate form, such information could be used to complement national health targets by providing a measure based on health status (quality of life) rather than mortality or disease prevalence alone. Therefore, the policy makers can use the HRQOL measures and the resulting data from this study to minimise health disparities and allocate resources among competing health programme based on burden of physical or mental health problems in a specific group. ${ }^{55}$

The lower health status reported by female, less educated, unemployed and low-income groups may indicate higher levels of stress in these groups. ${ }^{17}$ Other potential contributing factors that are known to influence health status are living conditions, gross domestic product per capita, inequities in income distributions and access to healthcare. ${ }^{56-61}$ Therefore, public health initiatives should focus on intersectoral approaches to address issues of education, generating more avenues for employment and improving the quality and access of primary healthcare.

Lastly, the issue of 'clinical' or 'policy' relevance of the difference in EQ5D measures needs much discourse. For example, if the VAS in two groups of the population is 5 or 10 points different from each other, we cannot make a clinical judgement on how much these two groups would differ in their actual health status. These issues relate to determining a minimally significant difference/change in HRQOL and needs investigation in future studies. However, because of HRQOL sensitivity to time trends as shown in previous studies, ${ }^{62-64}$ these measures are also likely to be useful in determining the effect of major population-based policies or interventions.

\section{CONCLUSION}

HRQOL appears to be lower with higher age and among women in South Asia. Our data demonstrate significantly lower HRQOL in key demographic groups and those with chronic conditions, which are consistent with previous studies. These data provide insights on inequalities in population health status, and potentially reveal unmet needs in the community to guide health policies.

Author affiliations
${ }^{1}$ Centre for Control of Chronic Conditions (4C), New Delhi, India
${ }^{2}$ Public Health Foundation of India, New Delhi, India
${ }^{3}$ Centre for Chronic Disease Control, New Delhi, India
${ }^{4}$ Department of Endocrinology and Metabolism, All India Institute of Medical
Sciences, New Delhi, Delhi, India
${ }^{5}$ Hubert Department of Global Health, Emory University, Atlanta, Georgia, USA
${ }^{6}$ Department of Epidemiology, Rollins School of Public Health, Emory University,
Atlanta, Georgia, USA
${ }^{7}$ Madras Diabetes Research Foundation and, Dr. Mohan's Diabetes Specialties
Centre, Chennai, Tamil Nadu, India
${ }^{8}$ Department of Community Health Sciences, Aga Khan University, Karachi, Pakistan
${ }^{9}$ School of Medicine, University of Washington, Seattle, Washington, USA
${ }^{10}$ London School of Hygiene and Tropical Medicine, London, United Kingdom

Contributors KS, DP, MKA, RS, NT and KMVN conceptualised and designed the study. KS wrote the first draft of the manuscript. KS and DK performed statistical analysis. RS, VSA, MKA, RP, VM, MMK, MDS, NT, KMVN and DP contributed 
significantly in the revision of the manuscript. All authors have approved the submission of this version of the manuscript.

Funding The CARRS Study was funded in whole or in part by the National Heart, Lung, and Blood Institute of the National Institutes of Health, Department of Health and Human Services (contract no HHSN268200900026C) and the United Health Group (Minneapolis, Minnesota, USA). RS is supported by a Wellcome Trust Capacity Strengthening Strategic Award Extension phase to the Public Health Foundation of India and a consortium of UK universities (WT084754/Z/08/A).

Competing interests None declared.

Ethics approval The CARRS study has obtained institutional ethics approval from each of the participating institutions: Public Health Foundation of India, All India Institute of Medical Sciences, New Delhi, India; Madras Diabetes Research Foundation, Chennai, India; Aga Khan University, Karachi; Rollins School of Public Health, Emory University, USA.

Provenance and peer review Not commissioned; externally peer reviewed.

Data sharing statement KS, DK and DP have access to study data set and statistical code. Any request for data sharing should be addressed to the corresponding author (DP)

Open Access This is an Open Access article distributed in accordance with the terms of the Creative Commons Attribution (CC BY 4.0) license, which permits others to distribute, remix, adapt and build upon this work, for commercial use, provided the original work is properly cited. See: http://creativecommons.org/ licenses/by/4.0/

(C) Article author(s) (or their employer(s) unless otherwise stated in the text of the article) 2017. All rights reserved. No commercial use is permitted unless otherwise expressly granted.

\section{REFERENCES}

1. Rabin R, Charro Fde, de Charro F. EQ-5D: a measure of health status from the EuroQol Group. Ann Med 2001;33:337-43.

2. Barker AEJ. Clinical Lecture on Permanent Subcutaneous Suture of the Patella for Recent Fracture: Delivered at University College Hospital. BMJ 1892;1:425-8.

3. Kaplan RM, Anderson JP. A general health policy model: update and applications. Health Serv Res 1988;23:203-35.

4. Coons SJ, Rao S, Keininger DL, et al. A comparative review of generic quality-of-life instruments. Pharmacoeconomics 2000;17:13-35.

5. Prabhakaran D, Jeemon P, Roy A. Cardiovascular diseases in India: current epidemiology and future directions. Circulation 2016;133:1605-20.

6. Fortin M, Lapointe L, Hudon C, et al. Multimorbidity and quality of life in primary care: a systematic review. Health Qual Life Outcomes 2004;2:51.

7. Alonso J, Ferrer M, Gandek B, et al. Health-related quality of life associated with chronic conditions in eight countries: results from the International Quality of Life Assessment (IQOLA) project. Qual Life Res 2004;13:283-98.

8. Schultz SE, Kopec JA. Impact of chronic conditions. Health Rep 2003;14:41-53.

9. Patrick DL, Deyo RA. Generic and disease-specific measures in assessing health status and quality of life. Med Care 1989;27(3 Suppl):S217-32.

10. Horsman J, Furlong W, Feeny D, et al. The Health Utilities Index (HUI): concepts, measurement properties and applications. Health Qual Life Outcomes 2003;1:54.

11 Furlong WJ, Feeny DH, Torrance GW, et al. The Health Utilities Index (HUI) system for assessing health-related quality of life in clinical studies. Ann Med 2001;33:375-84.

12. Brazier J, Roberts J, Deverill M. The estimation of a preferencebased measure of health from the SF-36. J Health Econ 2002;21:271-92.

13. McHorney CA. Health status assessment methods for adults: past accomplishments and future challenges. Annu Rev Public Health 1999;20:309-35.

14. The World Health Organization Quality of Life Assessment (WHOQOL). Development and general psychometric properties. Soc Sci Med 1998;46:1569-85.

15. The World Health Organization Quality of Life assessment (WHOQOL). Position paper from the World Health Organization. Soc Sci Med 1995;41:1403-9.
16. Study protocol for the World Health Organization project to develop a Quality of Life assessment instrument (WHOQOL). Qual Life Res 1993;2:153-9.

17. Centers for Disease Control and Prevention. Measuring healthy days: Population assessment of health-related quality of life. Centers for Disease Control and Prevention. AtlantaGeorgia 2000.

18. Gandek B, Sinclair SJ, Kosinski M, et al. Psychometric evaluation of the SF-36 health survey in Medicare managed care. Health Care Financ Rev 2004;25:5-25.

19. Nair M, Ali MK, Ajay VS, et al. CARRS Surveillance study: design and methods to assess burdens from multiple perspectives. BMC Public Health 2012;12:701.

20. ISPOR 2nd Latin America Conference. Abstracts. Value Health 2009;12:A483-534.

21. Patel SA, Shivashankar R, Ali MK, et al. CARRS Investigators. Is the "south Asian phenotype" unique to south Asians? Comparing Cardiometabolic Risk Factors in the CARRS and NHANES Studies. Glob Heart 2016;11:89-96.

22. Deepa M, Grace M, Binukumar B, et al. High burden of prediabetes and diabetes in three large cities in South Asia: the Center for cArdiometabolic Risk Reduction in South Asia (CARRS) study. Diabetes Res Clin Pract 2015;110:172-82.

23. Berg CJ, Ajay VS, Ali MK, et al. A cross-sectional study of the prevalence and correlates of tobacco use in Chennai, Delhi, and Karachi: data from the CARRS study. BMC Public Health 2015;15:483.

24. Ali MK, Bhaskarapillai B, Shivashankar R, et al. Socioeconomic status and cardiovascular risk in urban south Asia: the CARRS study. Eur J Prev Cardiol 2016;23:408-19.

25. Kind P, Dolan P, Gudex C, et al. Variations in population health status: results from a United Kingdom national questionnaire survey. BMJ 1998;316:736-41.

26. Sun $H$, Zhang $Q$, Luo $X$, et al. Changes of adult population health status in China from 2003 to 2008. PLoS One 2011;6:e28411.

27. Sun S, Chen J, Johannesson M, et al. Regional differences in health status in China: population health-related quality of life results from the National Health Services Survey 2008. Health Place 2011;17:671-80.

28. Sun S, Chen J, Johannesson M, et al. Population health status in China: EQ-5D results, by age, sex and socio-economic status, from the National Health Services Survey 2008. Qual Life Res 2011;20:309-20.

29. Measuring Self-Reported Population Health: An International Perspective based on EQ-5D. In: Szende A, Williams A, eds. On behalf of: The EuroQol Group's International Task Forceon SelfReported Health, 2004.

30. Sayed BA, French MT. To your health!: re-examining the health benefits of moderate alcohol use. Soc Sci Med 2016;167:20-8.

31. Mauro PM, Canham SL, Martins SS, et al. Substance-use coping and self-rated health among US middle-aged and older adults. Addict Behav 2015;42:96-100.

32. Badia X, Herdman M, Kind P. The Influence of ill-health experience on the valuation of health. Pharmacoeconomics 1998;13:687-96.

33. Sullivan PW, Ghushchyan V. Preference-Based EQ-5D index scores for chronic conditions in the United States. Med Decis Making 2006;26:410-20.

34. Ko Y, Coons SJ. Self-reported chronic conditions and EQ-5D index scores in the US adult population. Curr Med Res Opin 2006;22:2065-71.

35. Sakthong $P$, Sonsa-ardjit N, Sukarnjanaset $P$, et al. Psychometric properties of the EQ-5D-5L in Thai patients with chronic diseases. Qual Life Res 2015;24:3015-22.

36. Tan Z, Liang Y, Liu S, et al. Health-related quality of life as measured with EQ-5D among populations with and without specific chronic conditions: a population-based Survey in Shaanxi Province, China. PLoS One 2013;8:e65958.

37. McPherson K, Myers J, Taylor WJ, et al. Self-valuation and societa valuations of health state differ with disease severity in chronic and disabling conditions. Med Care 2004;42:1143-51.

38. Lam JMC, Wodchis WP. The relationship of 60 disease diagnoses and 15 conditions to preference-based health-related quality of life in Ontario hospital-based long-term care residents. Med Care 2010;48:380-7

39. Hutchinson AF, Graco M, Rasekaba TM, et al. Relationship between health-related quality of life, comorbidities and acute health care utilisation, in adults with chronic conditions. Health Qual Life Outcomes 2015;13:69.

40. Hevey D, McGee HM, Horgan J. Relationship of initial level of distress to changes in health-related quality of life during cardiac rehabilitation or usual care. Psychosom Med 2007;69:793-7. 
41. Arnlind $\mathrm{MH}$, Nokela $\mathrm{M}$, Rehnberg $\mathrm{C}$, et al. The relationship between pharmaceutical costs, disease severity, and health-related quality of life in asthmatics in Swedish primary care. J Asthma 2006;43:585-91.

42. Mo F, Choi BCK, Li FCK, Fc L, et al. Using Health Utility Index (HUI) for measuring the impact on Health-Related Quality of Life (HRQL) among individuals with chronic diseases. ScientificWorldJournal 2004:4:746-57.

43. Lubetkin El, Jia H, Franks $\mathrm{P}$, et al. Relationship among sociodemographic factors, clinical conditions, and health-related quality of life: examining the EQ-5D in the U.S. general population. Qual Life Res 2005;14:2187-96.

44. Jia H, Lubetkin El. The impact of obesity on health-related quality-of-life in the general adult US population. J Public Health 2005;27:156-64.

45. Sc W, Cy L, Ds K. The agreement between self-reporting and clinical diagnosis for selected medical conditions among the elderly in Taiwan. Public Health 2000;114:137-42.

46. Molenaar EA, Ameijden EJCV, Grobbee DE, et al. Comparison of routine care self-reported and biometrical data on hypertension and diabetes: results of the Utrecht Health Project. Eur J Public Health 2007;17:199-205.

47. Robinson JR, Young TK, Roos LL, et al. Estimating the burden of disease. Comparing administrative data and self-reports. Med Care 1997;35:932-47.

48. Okura Y, Urban LH, Mahoney DW, et al. Agreement between selfreport questionnaires and medical record data was substantial for diabetes, hypertension, myocardial infarction and stroke but not for heart failure. J Clin Epidemiol 2004;57:1096-103.

49. Chen J, Wong CKH, McGhee SM, et al. A Comparison between the EQ-5D and the SF-6D in patients with chronic obstructive pulmonary disease (COPD). PLoS One 2014;9:e112389.

50. Salaffi F, Carotti M, Ciapetti A, et al. A comparison of utility measurement using EQ-5D and SF-6D preference-based generic instruments in patients with rheumatoid arthritis. Clin Exp Rheumatol 2011;29:661-71.

51. Wu J, Han Y, Zhao F-L, et al. Validation and comparison of EuroQoL-5 dimension (EQ-5D) and Short Form-6 dimension (SF6D) among stable angina patients. Health Qual Life Outcomes 2014;12:156.

52. Petrou $S$, Hockley $C$. An investigation into the empirical validity of the EQ-5D and SF-6D based on hypothetical preferences in a general population. Health Econ 2005;14:1169-89.
53. Obradovic M, Lal A, Liedgens $H$. Validity and responsiveness of Euro Qol-5 Dimension (EQ-5D) versus Short Form-6 Dimension (SF-6D) questionnaire in chronic pain. Health Qual Life Outcomes 2013;11:110.

54. Kuspinar A, Mayo NE. A review of the psychometric properties of generic utility measures in Multiple sclerosis. Pharmacoeconomics 2014;32:759-73.

55. Rothberg AE, McEwen LN, Kraftson AT, et al. The impact of weight loss on health-related quality-of-life: implications for costeffectiveness analyses. Qual Life Res 2014;23:1371-6.

56. Kindig DA BB, Remington PL. Mobilizing Action Toward Community Health (MATCH): metrics, incentives, and partnerships for population health.. Prev Chronic Dis 2010;7(5.

57. Hennessy $\mathrm{CH}$, Moriarty DG, Zack MM, et al. Measuring healthrelated quality of life for public health surveillance. Public Health Rep 1994;109:665-72.

58. Dominick KL, Ahern FM, Gold CH, et al. Relationship of healthrelated quality of life to health care utilization and mortality among older adults. Aging Clin Exp Res 2002;14:499-508.

59. Prazeres F, Santiago L. Relationship between health-related quality of life, perceived family support and unmet health needs in adult patients with multimorbidity attending primary care in Portugal: a multicentre cross-sectional study. Health Qual Life Outcomes 2016;14:156.

60. Polat Ülkü, Bayrak Kahraman B, Kaynak İlknur, et al. Relationship among health-related quality of life, depression and awareness of home care services in elderly patients. Geriatr Gerontol Int 2016;16:1211-9.

61. Lim J-won, Paek M-so. The relationship between communication and health-related quality of life in survivorship care for ChineseAmerican and Korean-American breast cancer survivors. Support Care Cancer 2013;21:1157-66.

62. Jia H, Lubetkin El. Time trends and seasonal patterns of healthrelated quality of life among U.S. adults. Public Health Rep 2009;124:692-701.

63. Ford ES, Mokdad AH, Li C, et al. Gender differences in coronary heart disease and health-related quality of life: findings from 10 states from the 2004 behavioral risk factor surveillance system. $J$ Womens Health (Larchmt) 2008;17:757-68.

64. Zahran HS, Kobau R, Moriarty DG, et al. Health-related quality of life surveillance-United States, 1993-2002. MMWR Surveill Summ 2005;54:1-35. 